\title{
HISTÓRIA DE UMA INSTITUIÇÃO ESCOLAR SECUNDÁRIA E SUA CULTURA MATERIAL: O GINÁSIO MINEIRO DE UBERLÂNDIA (1920-1960) ${ }^{1}$
}

\author{
Giseli Cristina do Vale Gatti* \\ Geraldo Inácio Filho** \\ Décio Gatti Júnior***
}

\begin{abstract}
RESUMO
Trata-se da comunicação de reflexões teórico-metodológicas sobre as possibilidades do exame de artefatos escolares, tomados como objetos e documentos históricos, utilizados no processo de objetivação de investigação sobre importante instituição escolar do ensino secundário de Minas Gerais, no Brasil, a saber: o Ginásio Mineiro de Uberlândia. Nesse sentido, o conjunto de artefatos escolares constitui a base empírica de investigação de maior envergadura, na direção da percepção das práticas escolares disseminadas nos diferentes momentos da escola, em correspondência relativa ao processo de alteração das finalidades educacionais mais amplas. Compõem-se de objetos tornados documentos históricos visualizados diretamente, tais como, o edifício escolar, os troféus conquistados pelas equipes esportivas da escola, as placas de formatura, os equipamentos de áudio-visual, os livros escolares, os diários e os livros de

\footnotetext{
${ }^{1}$ Versão modificada e ampliada do trabalho apresentado em 21 de junho de 2008 na mesa coordenada intitulada "Escolas, escolarizações e utensilagens materiais" no VII Congresso Luso-Brasileiro de História da Educação realizado na Universidade do Porto, Portugal.

* Mestre e doutoranda em Educação na Universidade Federal de Uberlândia e Bolsista da FAPEMIG. E-mail: giseli@faced.ufu.br

** Doutor em Educação pela UNICAMP e Professor de História da Educação da Universidade Federal de Uberlândia. Bolsista de Produtividade em Pesquisa do CNPq - Nível 2. E-mail: gifilho@faced.ufu.br

*** Doutor em Educação pela PUC-SP e Professor de História da Educação da - Nível 2. E-mail: degatti@ufu.br
} Universidade Federal de Uberlândia. Bolsista de Produtividade em Pesquisa do CNPq
\end{abstract}


matrícula. Além disso, comportam artefatos escolares largamente presentes no cotidiano da escola, mas que foram apreendidos indiretamente, por meio, sobretudo, da farta iconografia relacionada à escola, em coleções da própria escola, dos arquivos públicos (municipal e da universidade) e, também, dos acervos particulares, especialmente de ex-alunos, por meio da qual é possível relacionar diferentes uniformes escolares, vinculados a exercícios de formação diferenciados, em estreito vínculo com aos diversos ditames político-ideológicos da época em referência; objetos de ensino de utilizados nos laboratórios destinados as aulas práticas de Química e de Física; utensílios destinados às práticas esportivas largamente realizadas na escola; instrumentos musicais e uniformes utilizados pela fanfarra mantida pela escola, vestimentas e decoração utilizadas nos bailes de formatura promovidos na escola; vestimentas utilizadas pelos professores em seu cotidiano.

PALAVRAS-CHAVE: Instituição. Escola. Cultura Material. Artefatos Escolares. Iconografia.

\begin{abstract}
This study relates theoretical-methodological reflections on the possibilities of examination of school artifacts, taken as objects and historical documents, used in the process of objectifying investigation regarding an important secondary school institution in Minas Gerais, Brazil, namely, the Ginásio Mineiro (Lower Secondary School) of Uberlandia. In this sense, the set of school artifacts constitutes the empirical base of investigation of greater scope in the direction of perception of school practices disseminated at different times of the school, in relative correspondence to the process of alteration of the broader educational purposes. It is composed of objects which have become directly viewed as historical documents, such as the school building, the trophies won by the school sports teams, the graduation plaques, the audio-visual equipment, the school books, the daily records and the enrollment books. In addition, there are other school artifacts amply present in the day-to-day life of the school but that were grasped indirectly, above all by means of abundant iconography related
\end{abstract}


to the school, in collections from the school itself, from public archives (municipal and university) and also from private collections, especially from former students, through which it is possible to relate different school uniforms, connected to the exercise of differentiated school formation, in strict connection with the diverse political-ideological dictates of the time in reference; teaching objects used in the laboratories dedicated to practical classes of Chemistry and Physics; utensils dedicated to sporting practices largely undertaken within the school; musical instruments and uniforms used by the brass band maintained by the school; apparel and decorations used in the graduation dances promoted within the school; apparel used by teachers in daily activity.

KEYWORDS: Institution. School. Material Culture. School Artifacts. Iconography.

\section{Introdução}

A pesquisa em História da Educação e particularmente em História das Instituições Escolares, passou por constantes transformações nos últimos anos, deixando de lado o caráter laudatório, em se que produzia apenas uma descrição de fatos políticos e legais. Atualmente as pesquisas dessa área procuram levar em conta análise mais concreta dos fatos a partir de indícios históricos, principalmente no que tange a história de instituições escolares.

Nessa perspectiva, ganham corpo as pesquisas que tem como temática a história das instituições escolares; pesquisas como essa, procuram não apenas traçar a trajetória de determinada instituição escolar, mas também procurar entender qual a sua influência no processo de expansão e modernização das cidades.

Nóvoa (1999) afirma que há uma espécie de redescoberta da especificidade das temáticas escolares, do papel dos diferentes atores educativos e da sua experiência; uma tendência às práticas de história intelectual e cultural, a partir de novas concepções teóricas; uma revalorização das abordagens comparadas (p. 3-4).

Portanto, ao historiar uma instituição educativa, procura-se fazer uma interpretação ou uma releitura de seu passado, levando em conta os 
seus diversos atores, alunos, professores, diretores e corpo administrativo.

Nessa direção, a compreensão do termo instituição torna-se relevante. Do Dicionário Houaiss podem-se destacar as seguintes acepções:

Diacronismo: antigo: ato de instruir, de educar; ato ou efeito de instituir ('dar começo a'); criação; Rubrica: sociologia. cada um dos costumes ou estruturas sociais, estabelecidas por lei ou consuetudinariamente, que vigoram num determinado Estado ou povo. Ex.: $<$ a i. da família $>$ $<\mathrm{a}$ i. do casamento $><\mathrm{a}$ i. do dote $><\mathrm{a}$ i. da primogenitura $>$; estrutura material e humana que serve à realização de ações de interesse social ou coletivo; organização, estabelecimento Ex.: <uma i. de caridade> $<$ i. civil, militar, religiosa, penal etc. $>$; estabelecimento destinado ao ensino, à educação; escola, instituto, educandário. Ex.: i. para surdosmudos. Dermeval Saviani (2005, p. 28), por seu turno, a partir de Torrinha, apresenta quatro acepções, a saber: 1. Disposição; plano; arranjo; 2. Instrução; ensino; educação; 3. Criação; formação; 4. Método, sistema, escola, seita, doutrina.

Percebe-se que o termo, compreende, entre suas acepções, a ideia de educação, pois que se trata de instituir uma ordem de pensamento, de comportamentos desejáveis a partir dos grupos sociais que controlam a instituição. Porém, o emprego da locução "instituição escolar", aparentemente, tem conotação distintiva, com a finalidade de precisar melhor a comunicação.

Ao tratar do conceito de instituição educativa, Saviani, com base nas observações de Bourdieu e Passeron, afirma que

Levando em conta o caso particular da educação, notamos que se trata de uma realidade irredutível nas sociedades humanas que se desenvolve, originariamente, de forma espontânea, assistemática, informal, portanto, de maneira indiferenciada em relação às demais práticas sociais. A institucionalização dessa forma originária de educação dará origem às instituições educativas. Estas correspondem, então, a uma educação de tipo secundário, derivada da educação de tipo primário exercida de modo difuso e inintencional. (SAVIANI, 2005, p. 5). 
Complementarmente, Saviani (2005) toma as instituições de modo geral, e a instituição escolar de modo particular, como uma unidade de ação, especificando-a como um sistema de práticas "um sistema de práticas com seus agentes e com os meios e instrumentos por eles operados tendo em vista as finalidades por elas perseguidas" (p. 28), bem como, ainda com Bourdieu e Passseron, destaca a importância da percepção de considerar a escola como uma entre outras instâncias educativas que atuam nos processos de formação humana postos em disputa no território social, conforme se pode perceber abaixo:

Quando consideramos a instituição educativa, isto é, quando tomamos a educação na sua especificidade, como ação propriamente pedagógica, cuja forma mais conspícua se expressa na escola, observamos que esse destacar-se da atividade educativa em relação aos demais tipos de atividade não implica necessariamente que as instituições propriamente educativas passem a deter o monopólio exclusivo do exercício do trabalho pedagógico secundário. Na verdade, o que constatamos é uma imbricação de instituições de diferentes tipos, não especificamente educativas que, nem por isso, deixam de cuidar, de algum modo, da educação. Assim, para além da instituição familiar votada, pelas suas próprias características, ao exercício da educação espontânea, vale dizer, do trabalho pedagógico primário, encontramos instituições como sindicatos, igrejas, partidos, associações de diferentes tipos, leigas e confessionais, que, além de desenvolver atividade educativa informal, podem, também, desenvolver trabalho pedagógico secundário, seja organizando e promovendo modalidades específicas de educação formal, seja mantendo escolas próprias em caráter permanente. Nesse âmbito, as instituições que se destacam nitidamente entre as demais, são, sem dúvida, a Igreja e o Estado. (SAVIANI, 2005, p. 5).

Justino Magalhães também faz dois apontamentos em relação ao conceito de instituição escolar que cabe aqui destacar:

No plano histórico, uma instituição educativa é uma complexidade espaço-temporal, pedagógica, organizacional, onde se relacionam elementos materiais e humanos, mediante papéis e representações diferenciados, entretecendo e projetando futuro(s), (pessoais), através de expectativas institucionais. É um lugar de permanentes tensões. 
[...] são projetos arquitetados e desenvolvidos a partir de quadros sócio-culturais. (MAGALHÃES, 1998, p. 61-2)

$[\ldots]$

Por educação-instituição não pode deixar de traduzir-se essencialmente o que há de permanente, focalizando na longa duração. Contudo a relação educativa é uma dialética entre o dado e ato, é atualização; é uma relação instituinte entre a realidade envolvente, as estruturas, as tradições, as expectativas socioculturais (o instituído), por meio da dialética contratual (instituição), por ação dos sujeitos individuais e grupais (instituinte). (MAGALHÃES, 2004, p. 60).

Através da reflexão elaborada por Magalhães, o espaço escolar não pode ser tomado apenas como um local de reprodução mecânica das ideias sociais dominantes, mas também um local onde ocorrem resistências. A cultura material em necessária articulação com os indivíduos e os usos escolares dos artefatos materiais também aparece na reflexão do autor. Ainda na perspectiva de Justino Magalhães,

A abordagem dos processos de formação e de evolução das instituições educativas constitui um domínio do conhecimento historiográfico em renovação no quadro da História da Educação. Uma renovação onde novas formas de questionar-se cruzam com um alargamento das problemáticas e com uma sensibilidade acrescida à diversidade dos contextos e à especificidade dos modelos e práticas educativas. Uma abordagem que permita a construção de um processo histórico que confira uma identidade às instituições educativas". (MAGALHÃES, 1996, p. 1)

Trata-se, segundo Magalhães, de uma “[...] história construída da(s) memória(s) para o arquivo e do arquivo para a memória", com a finalidade de efetivar uma síntese multidimensional que demonstre um determinado itinerário pedagógico, uma identidade histórica específica, um processo em evolução e um projeto pedagógico (MAGALHÃES, 1998, p. 61). Considera ainda que 
Compreender e explicar a existência histórica de uma instituição educativa é, sem deixar de integrá-la na realidade mais ampla que é o sistema educativo, contextualizá-la, implicando-a no quadro de evolução de uma comunidade e de uma região, é por fim sistematizar e (re)escrever-lhe o itinerário de vida na sua multidimensionalidade, conferindo um sentido histórico". (MAGALHÃES, 1996, p. 2)

A partir das ideias expostas por Magalhães (1998), o autor dá destaque às categorias de análise, que são mais comumente usadas em pesquisas que tem como foco central as instituições educativas. São elas:

- Espaço (local/lugar, edifício, topografia);

- Tempo (calendário, horário, agenda antropológica);

- Currículo (conjunto das matérias lecionadas, métodos, tempos, etc. ou racionalidade da prática);

- Modelo Pedagógico (construção de uma racionalidade complexa que articula a lógica estruturante interna com as categorias externas que a constituem - tempo, lugar e ação;

- Professores (recrutamento, profissionalização; formação, organização, mobilização, história de vida, itinerários, expectativas, decisões, compensações);

- Manuais Escolares;

- Públicos (cultura, forma de estimulação e resistências);

- Dimensões (níveis de apropriação, transferências da cultura escolar, escolarização, alfabetização, destinos de vida).

$\mathrm{Na}$ linha de pesquisadores brasileiros cabe aqui destacar as categorias de análise utilizadas por Paolo Nosella e Ester Buffa em suas investigações:

- Origem, criação, construção e instalação;

- Prédio (projeto, implantação, estilo e organização do espaço);

- Mestres e funcionários (perfil);

- Clientela (alunos, ex-alunos);

- Saber (conteúdos escolares), 
- Evolução,

- Vida (cultura escolar: prédio, alunos, professores e administradores, normas).

Vinculam-se a estas categorias, evidentemente, outras, como a de organização e vida econômica, política e cultural da cidade e, sobretudo, o destino profissional dos alunos, pois que, segundo Nosella e Buffa (2005, p. $365)$ é "[...] essencial tanto indagar a origem social e o destino profissional dos atores de uma instituição escolar para se definir seu sentido social, quanto analisar os currículos utilizados para compreender seus objetivos sociais)".

Dessa maneira, as interpretações construídas por pesquisadores estrangeiros e brasileiros têm seguido um roteiro de pesquisa similar, em que se destacam preocupações com os processos de criação e do desenvolvimento (ciclo de vida) das instituições educativas; a configuração e as mudanças ocorridas na arquitetura do prédio escolar; os processos de conservação e mudança do perfil dos docentes; os processos de conservação e mudança do perfil dos alunos; os destinos profissionais e pessoais dos alunos, as formas de configuração e transformação do saber veiculado nestas instituições de ensino etc.

O desenvolvimento de pesquisas que tem como objeto de pesquisa as instituições escolares é significativo, para a construção de uma Nova História da Educação Brasileira, pois leva em conta as especificidades regionais e as singularidades locais e institucionais, que podem ser consideradas importantes para o contexto nacional.

\section{Cultura Escolar: normas e finalidades sócio-históricas em meio aos artefatos escolares}

A escola é considerada uma transmissora de cultura, pois é no espaço escolar que acontece o processo de socialização, a disseminação de conhecimento, normas, valores e ritos. A partir desse pressuposto é possível afirmar que a escola é possuidora de uma cultura escolar e de identidade própria.

Dominique Julia descreve a cultura escolar como sendo um conjunto de normas que definem conhecimentos a ensinar e condutas a inculcar, e um 
conjunto de práticas que permitem a transmissão desses conhecimentos e a incorporação desses comportamentos. (JULIA, 2001, p.9).

Nesse sentido a afirmação de Julia nos faz pensar e nos remete a tentar identificar os saberes e condutas, disseminados nas várias instituições de ensino, de acordo com cada época e se esse "habitus" aplicado no interior das instituições refletia-se no âmbito da sociedade.

Dominique Julia (2001, p.9) aponta três eixos de análise para entender a cultura escolar. A primeira delas esta relacionada às normas e finalidades que regem a escola. Nessa perspectiva, ao analisar o conjunto de normas que estruturam o espaço escolar e seu regimento, é possível perceber a que veio essa instituição e qual a sua finalidade no contexto em que se insere.

Outro eixo apontado por Julia é avaliar o papel desempenhado pela profissionalização do trabalho, ou seja, qual era a sua formação e seus intinerários de vida e por fim analisar os conteúdos ensinados e as práticas escolares, pois por meio delas é possível compreender como se dava as práticas educativas utilizadas em sala de aula e quais eram seus objetivos.

Como enfatiza Dominique Julia, utilizando-se de uma metáfora, as disciplinas escolares podem ser consideradas a "caixa preta" da escola. Já Viñao Frago vê na cultura escolar,

[...] modos de pensar e atuar que proporcionam a seus componentes estratégias e pautas para desenvolver-se tanto nas aulas como fora delas - no resto do recinto escolar e no mundo acadêmico - e integrarse na vida cotidiana das mesmas (2000a, p. 100).

Então a forma como a escola procura se organizar reforça os mecanismos geradores de adaptação e de dominação e são esses mecanismos que tem a função de informar os processos pedagógicos, organizativos, de gestão e de tomada de decisões que acontecem espaço interno da instituição escolar e que estão muito além do que está escrito na legislação educacional, isso porque cada escola tem uma maneira muito específica de exercer as suas normas internas.

Para Julia a cultura escolar, evidencia que a escola não é somente um lugar de transmissão de conhecimentos, mas é, ao mesmo tempo e

Educ. e Filos. Uberlândia, v. 23, n. 46, p. 119-144, jul./dez. 2009. 
talvez principalmente, um lugar de "[...] inculcação de comportamentos e de habitus" (JULIA, 2001, p. 14). A necessidade de conformação dos objetivos educacionais aos limites apresentados pela sociedade, em cada período da história, também tem impacto decisivo no estabelecimento da cultura escolar, pois ela é uma "[...] cultura conforme, e seria necessário traçar, a cada período, os limites que traçam a fronteira do possível e do impossível" (JULIA, 2001, p. 25).

Na perspectiva de Vinão Frago, a cultura escolar é entendida como um conjunto de práticas, normas, ideias e procedimentos que se expressam em modos de fazer e pensar o cotidiano da escola. E

[...] esses modos de fazer e de pensar - mentalidades, atitudes, rituais, mitos, discursos, ações - amplamente compartilhados, assumidos, não postos em questão e interiorizados, servem a uns e a outros para desempenhar suas tarefas diárias, entender o mundo acadêmico-educativo e fazer frente tanto às mudanças ou reformas como às exigências de outros membros da instituição, de outros grupos e, em especial, dos reformadores, gestores e inspetores (Viñao Frago, 2000a, p. 100).

Então, entende-se que toda instituição de ensino é portadora de uma cultura escolar, e nessa perspectiva pode-se afirmar que essa cultura escolar é determinante para dar identidade a essa instituição, escola está alicerçada em um conjunto de normas, valores, ritos e procedimentos pedagógicos que vão lhe dar uma característica única e portadora de cultura própria.

Em outras palavras, o cotidiano escolar, o que acontece nas salas de aula, nos intervalos, os comportamentos por ela disseminados vai determinar a cultura da escola. Nessa perspectiva Vinão Frago descreve a cultura como um

[...] mundo humanamente construído, mundo das instituições e dos signos no qual, desde a sua origem, se banha o indivíduo humano, tão somente por ser humano, e que constitui como que sua segunda matriz (1998, p.168).

Na perspectiva de Julia, a escola como instituição, não difere de outras instituições existentes em nossa sociedade, pois todas elas possuem 
histórias e trajetórias e funções sociais diferenciadas.

Nesse espaço institucional em que a cultura escolar ou cultura da escola é disseminada, as disciplinas escolares, com seus conteúdos específicos, têm papel significativo, pois como afirma Julia,

O estudo histórico das disciplinas escolares mostra que diante das disposições gerais atribuídas pela sociedade à escola, os professores dispõem de uma ampla liberdade de manobra: a escola não é lugar de rotina e da coação e o professor não é agente de uma didática que lhe seria imposta de fora. (2001, p. 33)

Julia, com essa afirmação, procura nos mostrar que apesar da pressão de agentes externos, é possível questionar a natureza de seu ensino, e que a única restrição aplicada a ele é em relação aos seus alunos, ou seja, que saberes funcionam e não funcionam diante desse público. (JULIA, 2001, p.33)

Então a escola como um espaço de produção de conhecimentos, tem em suas práticas educativas e em seus objetivos sociais, uma forma de disseminar sua cultura através de seus alunos, pois são eles os responsáveis em propagar a ideologia e a identidade da instituição educativa do qual fazem parte. André Chervel ilustra muito bem isso através da seguinte citação:

Se se pode atribuir um papel "estruturante" a função educativa da escola na história do ensino, é devido a uma propriedade das disciplinas escolares. $\mathrm{O}$ estudo dessa leva a pôr em evidência o caráter eminentemente criativo do sistema escolar e, portanto, a classificar no estatuto dos acessórios a imagem de uma escola encerrada na passividade, de uma escola receptáculo dos subprodutos culturais da sociedade [...] E porque o sistema escolar é detentor de um poder criativo insuficientemente valorizado até aqui, é que ele desempenha na sociedade um papel o qual não se percebeu que era duplo: de fato ele forma não somente os indivíduos, mas também uma cultura que vem por sua vez penetrar, moldar, modificar a cultura da sociedade global (CHERVEL, 1990, p.184).

Portanto a cultura disseminada pela escola será aquela capaz de transformar o contexto a sua volta, ou seja, aquela capaz transformar a 
sociedade através do tempo, do espaço, e dos sujeitos que é resultado da prática educativa, para o que concorre efetivamente o emprego de artefatos escolares decisivos, tais como o prédio escolar, as salas de aula, o pátio, a quadra e os laboratórios de ensino.

\section{Documentação e artefatos materiais preservados do Ginásio de Uberlândia}

A História das Instituições Escolares, bem como o estudo da cultura escolar de uma ou de uma série de instituições escolares constituem tendências recentes no campo da História da Educação brasileira, ao menos na perspectiva de um exame que supere uma análise pautada exclusivamente pelo estabelecimento de relações macro-societárias, com a entrada de uma rica dialética entre o particular e o geral, entre o cotidiano escolar e as finalidades sociais. Perspectiva nova que leva o historiador da Educação a busca, ao conhecimento e a utilização de amplos contingentes de evidências históricas (GATTI JR. e PESSANHA, 2005).

Constituem desse modo, fontes importantes para os processos de investigação sobre as instituições escolares ou mesmo sobre a cultura escolar, um amplo arsenal de documentos manuscritos, impressos, arquitetônicos, iconográficos, artefatos e orais (para estudos de períodos mais recentes), sendo que as mais comumente encontradas nas próprias instituições escolares apresentam: livros de ata (de aprovação escolar, de registro de matrícula, de reuniões pedagógicas, de reuniões do colegiado, de reuniões administrativas, de posse e designação, de ocorrências disciplinares), regimento escolar, correspondência enviada e recebida (ofícios, convites, circulares, comunicações), por livro de ponto (livro de controle de frequiência de professores e funcionários), livro de registro de freqüência escolar, grades curriculares, planos de aula e planos de curso, pastas de alunos (em que o conteúdo é a ficha cadastral do aluno e seu histórico escolar), termos de visita e inspeção, registro escolar (dados estatísticos sobre admissão, matrícula, aprovação, transferência), prédio escolar, carteiras, equipamentos de ensino e de laboratórios etc.

Além disso, as pesquisas sobre instituições escolares e, de modo especial, sobre instituições com grande importância local em um determinado período histórico, podem servir-se, quando possível, de 
evidências disponíveis em acervos dos arquivos públicos instalados na própria cidade ou no Estado da federação a qual a cidade está ou esteve vinculada, tais como iconografia, jornais impressos, relatórios etc. Convêm destacar ainda as possibilidades de consulta nos acervos das câmaras municipais, centros de documentação públicos e privados e, por fim, acervos particulares, em especial de antigos dirigentes, inspetores, funcionários, professores e alunos.

Porém, em especial nos acervos das escolas públicas, os pesquisadores comumente relatam problemas de conservação da documentação e da situação precária de guarda da mais antiga, dos equipamentos de ensino e mesmo da conservação do prédio escolar, muitas vezes descaracterizados em sua originalidade por reformas de planejamento e execução descuidados. A maior parte dos acervos escolares encontra-se em espaço físico inadequado, sem um local destinado exclusivamente ao arquivo de documentos e costumeiramente em salas que abrigam o acervo em caráter provisório, o que também significa, na maior parte das vezes, pouco cuidado na forma como são guardados os documentos, armazenados em caixas ou pastas de papelão, disponibilizados em armários e até mesmo jogados no chão, onde estão sujeitos à umidade, mofo e traças (MENDES, 2000; GATTI, 2001).

Contando com a boa vontade de profissionais da escola que se preocupam com a guarda e conservação da documentação, a organização do material a ser arquivado quando realizada, é feita quase sempre seguindo a ordem alfabética, justamente por ser uma maneira mais fácil de lidar com a documentação, sendo evidente que a inexistência de pessoal lotado na escola com bom conhecimento de arquivística, contribui sobremaneira para a falta de organização e de conservação dos acervos escolares.

Nesse sentido, torna-se cada vez mais necessário que se operem ações para sensibilizar aos gestores da educação pública, aos responsáveis pela direção e funcionamento da escola, o que inclui professores e alunos, para que se efetive o trabalho contínuo de preservação das fontes de interesse para a história da educação, pois que cada escola constrói e reconstrói sua identidade e relevância no processo de desenvolvimento de sua cidade ou região e, para a compreensão a posteriori desse papel exercido pelas instituições escolares, torna-se necessária à constituição de acervos documentais.

Educ. e Filos. Uberlândia, v. 23, n. 46, p. 119-144, jul./dez. 2009 
No que diz respeito especificamente a Escola Estadual de Uberlândia, a maior parte da documentação encontra-se no acervo da própria escola, sendo que a mais antiga, datada de 1915, encontrava-se arquivada, até meados da primeira década desse século, em um porão sujeito a forte ação da umidade, com presença de mofo, cupins e traças.

Felizmente, após o processo de restauração pelo qual passou recentemente o prédio da escola, a partir de financiamento da própria Secretaria de Estado da Educação de Minas Gerais, bem como o fato de que o edifício escolar constar como parte importante do patrimônio cultural da cidade, o antigo porão que fazia às vezes de arquivo foi desativado, sendo que a documentação que resistiu a ação da umidade e do mofo foi levada para uma grande sala que possui algumas divisões e que já estava sendo utilizada como arquivo há algum tempo. Porém, infelizmente, parte considerável da documentação anteriormente armazenada no referido porão, perdeu-se em função do excesso de umidade e do incorreto acondicionamento. Atualmente, a documentação corrente encontra-se adequadamente armazenada (FIG. 1) e a documentação antiga ainda carece de melhor guarda, organização e conservação (FIG. 2).

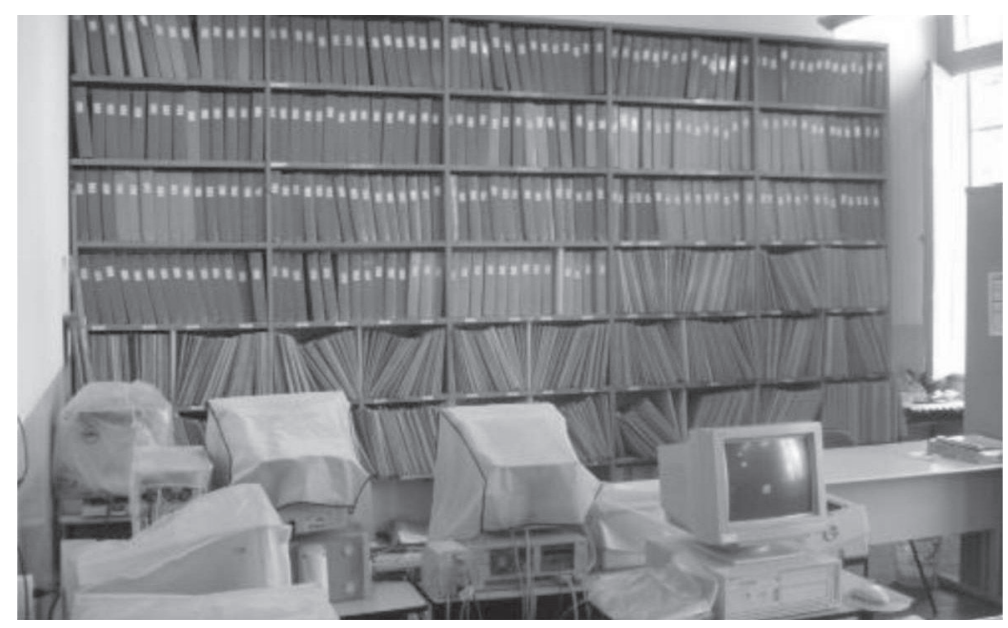

FIGURA 1 - Acervo de documentos correntes e atuais da Escola Estadual Uberlândia (Fotografia: Décio Gatti Júnior, em 11 de julho de 2007).

Educ. e Filos. Uberlândia, v. 23, n. 46, p. 119-144, jul./dez. 2009. 


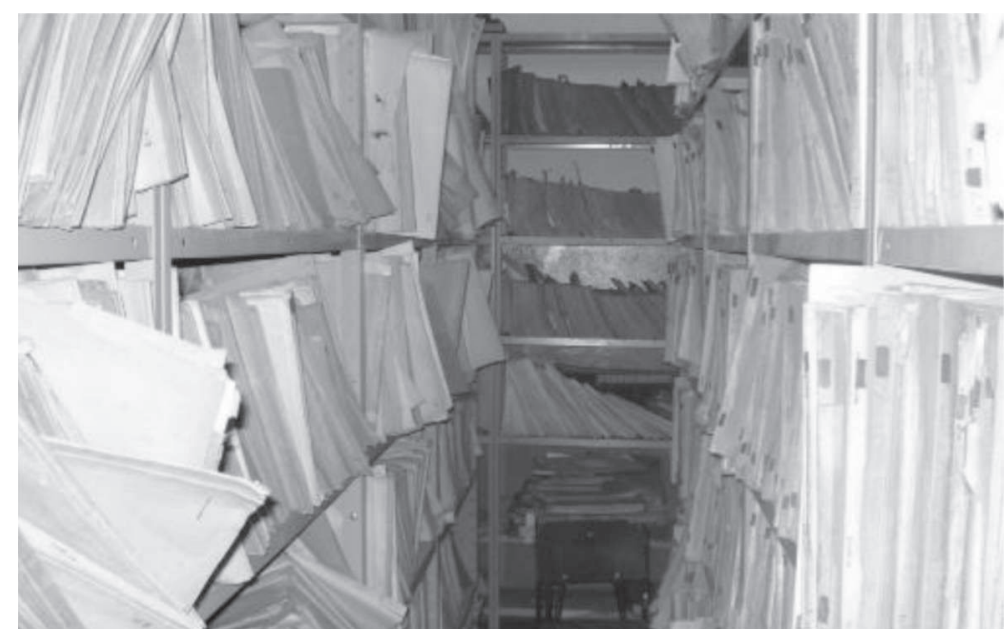

FIGURA 2 - Acervo provisório de documentos antigos da Escola Estadual Uberlândia (Fotografia: Décio Gatti Júnior, em 11 de julho de 2007).

Apesar da transferência de um ambiente para outro, a sala utilizada atualmente ainda não possui as condições adequadas para a guarda da documentação, mas já constituiu melhora em relação às condições anteriores.

Além disso, uma única funcionária da escola, dedicada e interessada, mas com relativa disponibilidade para o cuidado do arquivo, pois que acumula outras funções na escola e não possui ainda formação específica em arquivística.

Embora os problemas com o espaço físico para a guarda e organização da documentação persistam, os responsáveis pela escola têm consciência de que é necessário preservá-la, mas, dada às carências da escola pública, muitas vezes, outras prioridades são colocadas em primeiro plano. Em outras palavras, faz-se necessário não apenas conscientizar os dirigentes, alunos, professores e corpo administrativo da necessidade de organizar e preservar seus documentos mais antigos; é preciso que o Estado também compreenda que toda escola possui uma trajetória, uma história, identidades e que todos esses elementos são importantes para a formação e transformação de seus atores principais: os alunos. 
Há ainda documentação relevante referente à Escola Estadual Uberlândia no acervo do CDHIS/UFU - Centro de Documentação em História da Universidade Federal de Uberlândia (iconografia, sobretudo), no acervo do APMU - Arquivo Público Municipal de Uberlândia (jornais de época, sobretudo) e mesmo em uma série de acervos particulares de antigos professores e estudantes da escola, conforme os exemplos ilustrativos apresentados nas figuras 3,4 e 5 . Destaca-se que a iconografia apresenta elementos importantes da cultura material da escola, sendo que os artefatos apresentados, mesmo que desaparecidos, remontam a memória e tornam-se passíveis de interpretação.

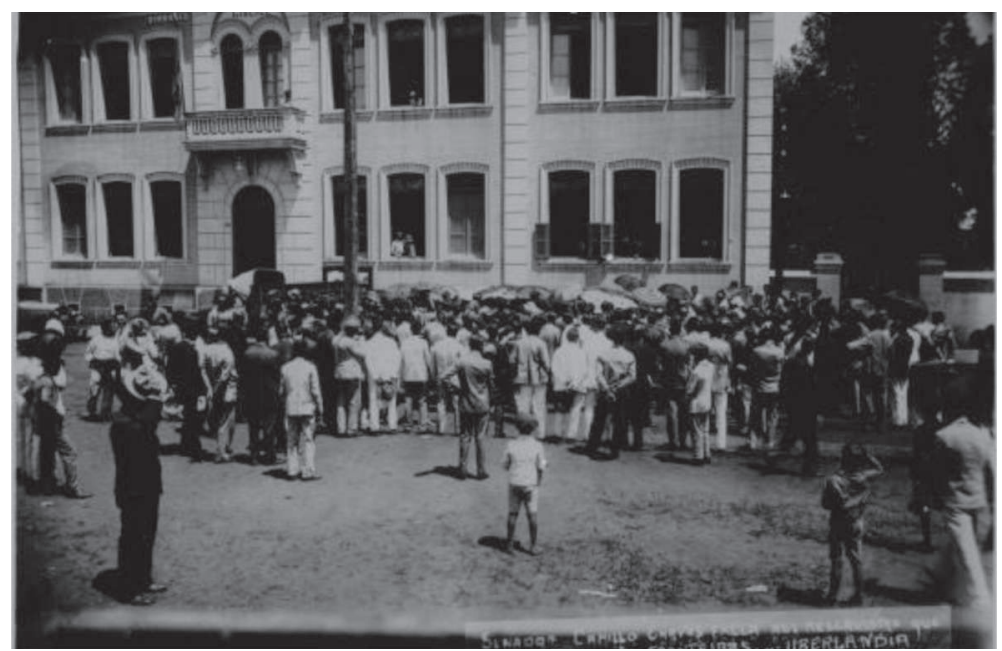

FIGURA 3 - Discurso do Senador Camilo Chaves, em 17 de outubro de 1930, aos reservistas que partem para as fronteiras, com a presença de populares (Acervo João Quituba do CDHIS/UFU) 


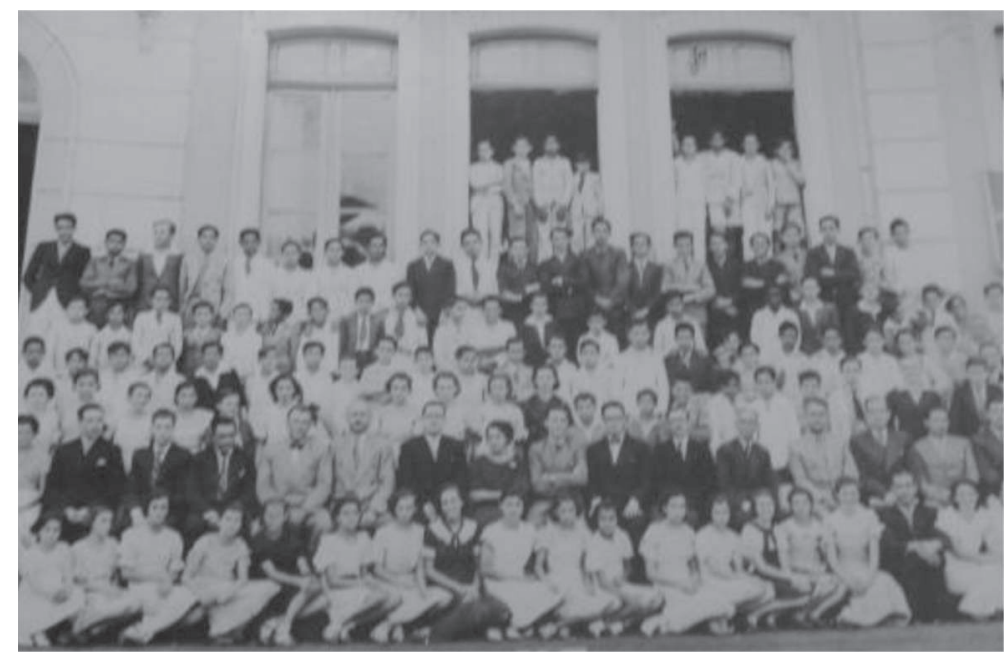

FIGURA 4 - Estudantes da Escola Estadual de Uberlândia, s/data (Acervo do Arquivo Público Municipal de Uberlândia).

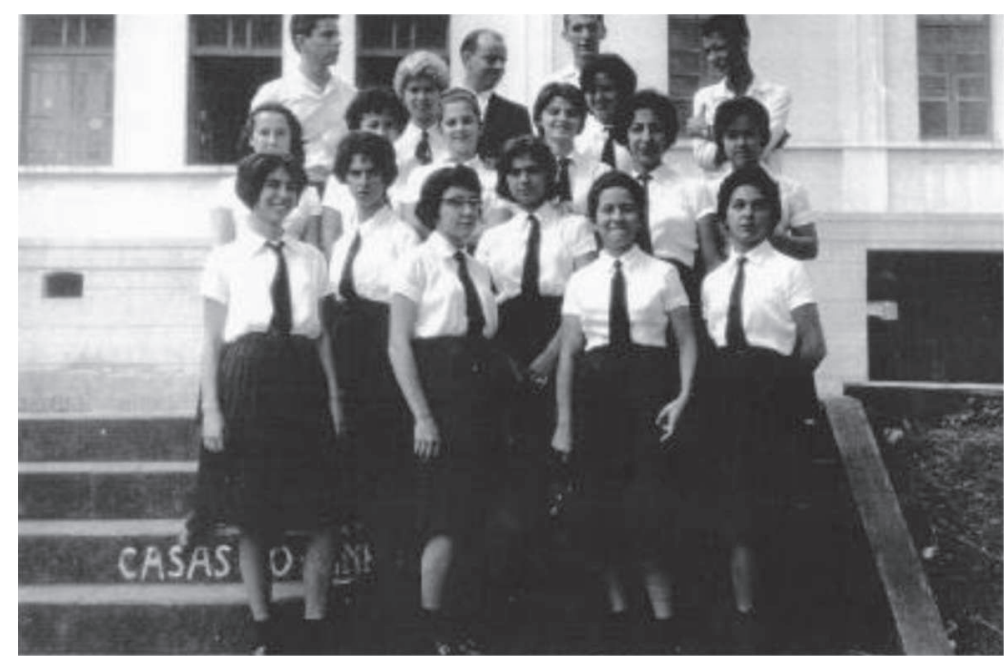

FIGURA 5 - Estudantes da Escola Estadual de Uberlândia ladeando o Prof. Saint Clair, em 1960 (Acervo Particular da Sra. Aparecida Portilho Salazar) 


\section{Cultura material percebida no prédio-monumento do Ginásio Mineiro de Uberlândia:}

O prédio, concluído em 1921, possuía dois andares, cinco salas de aula, um hall de entrada, uma diretoria, uma biblioteca, um teatro, uma sala para dissecações, uma sala de projeção, um museu de história natural e um laboratório com capacidade para vinte alunos, com localização em um terreno central, de modo que era possível vê-lo de qualquer ângulo, pois não havia outras construções em seu entorno.

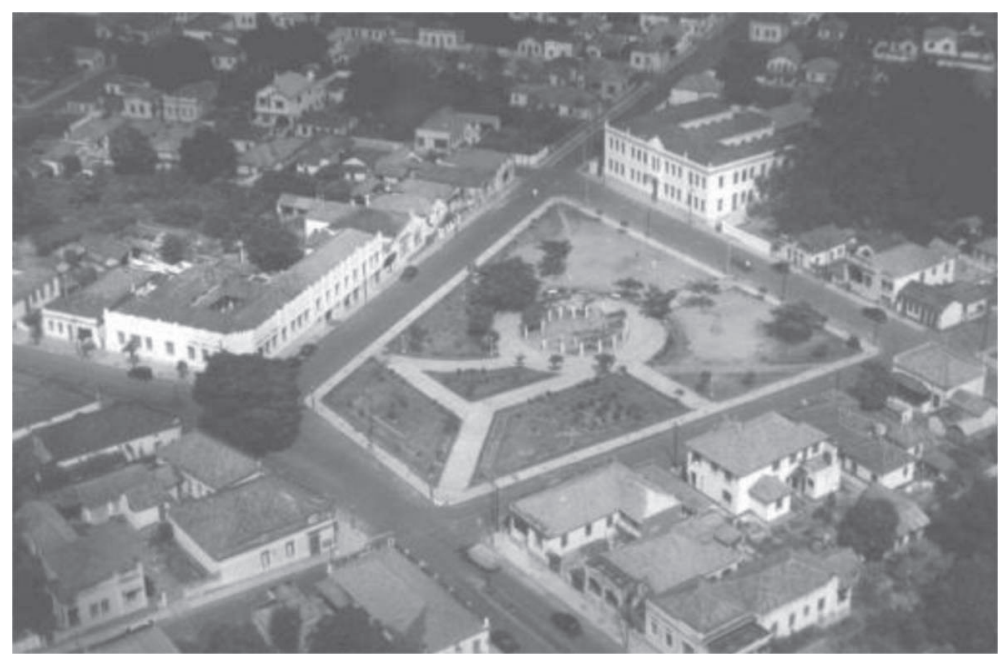

FIGURA 6 - Vista aérea do Ginásio Estadual de Uberlândia, na década de 1930 (Acervo do CDHIS/UFU - Centro de Documentação e Pesquisa em História).

A Escola Estadual de Uberlândia teve seu prédio tombado como Patrimônio Histórico Municipal em 2005, por meio da Lei $n^{\circ} 9.904$ de 13/06/2005 (UBERLÂNDIA, 2007b). Segundo está descrito no documento "Inventário de Proteção do Acervo Cultural - Minas Gerais - Brasil" (UBERLÂNDIA, 2007a) o prédio é excelente exemplar de uma arquitetura institucional de tipo eclética, com forte presença de estilemas neoclássicos, com localização na esquina da Praça Adolfo Fonseca com a Rua Teixeira Santana.

Educ. e Filos. Uberlândia, v. 23, n. 46, p. 119-144, jul./dez. 2009. 
A fachada principal da escola está voltada para a praça, possuindo dois pavimentos, com porão alto. Em sua fachada é possível visualizar a "porta central com verga de arco pleno encimada por duas janelas no nível do segundo pavimento, também com verga em arco pleno que se abre para um pequeno balcão. Possui duas aberturas centrais, com seis janelas de cada lado, com vergas de arco batido, distribuídas em dois panos marcados por pilastras adoçadas" (UBERLÂNDIA, 2007a). A fachada da escola (FIG. 2) é

[...] arrematada por ático contínuo, com acrotérios correspondentes aos cunhais e às pilastras adoçadas, ao centro existe um frontão de perfil recortado, sendo que na parte superior ostenta a Estrela da República e logo abaixo o ano de inauguração do edifício (1921).

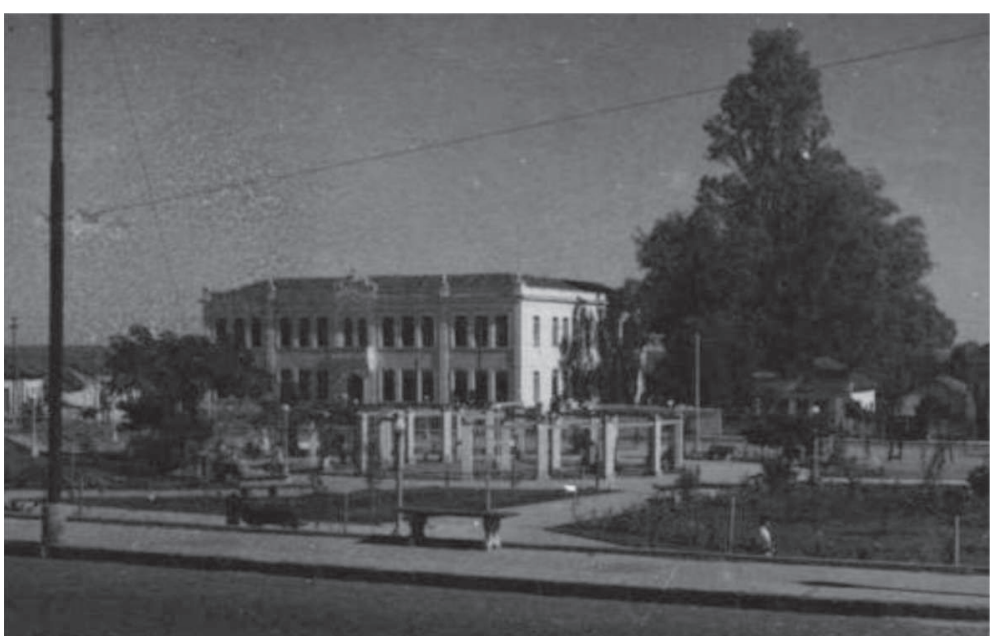

FIGURA 7 - Fotografia com vista da fachada do Ginásio Estadual de Uberlândia, na década de 1930 (Acervo João Quituba do CDHIS/UFU)

A planta da escola (FIG. 8), por seu turno,

[...] apresenta-se com uma fachada frontal, dividida em três pavilhões iguais que estão dispostos paralelamente, formando um "E" deitado. Sua construção emprega estrutura autoportante de tijolos maciços e alicerces de pedra (UBERLÂNDIA, 2007a). 
No passar dos anos, o prédio sofreu algumas reformas, de maior e de menor porte, sem, com isso, alterar sua estrutura original. Em 1942, sob a administração do Sr. Osvaldo Vieira Gonçalves, foram construídos uma quadra iluminada para a prática de basquete no período noturno, um galpão com palco, onde aconteciam os bailes, as peças de teatro e pequenas apresentações musicais. Todo o pátio da escola foi calçado e recebeu ainda pintura e reparos gerais.

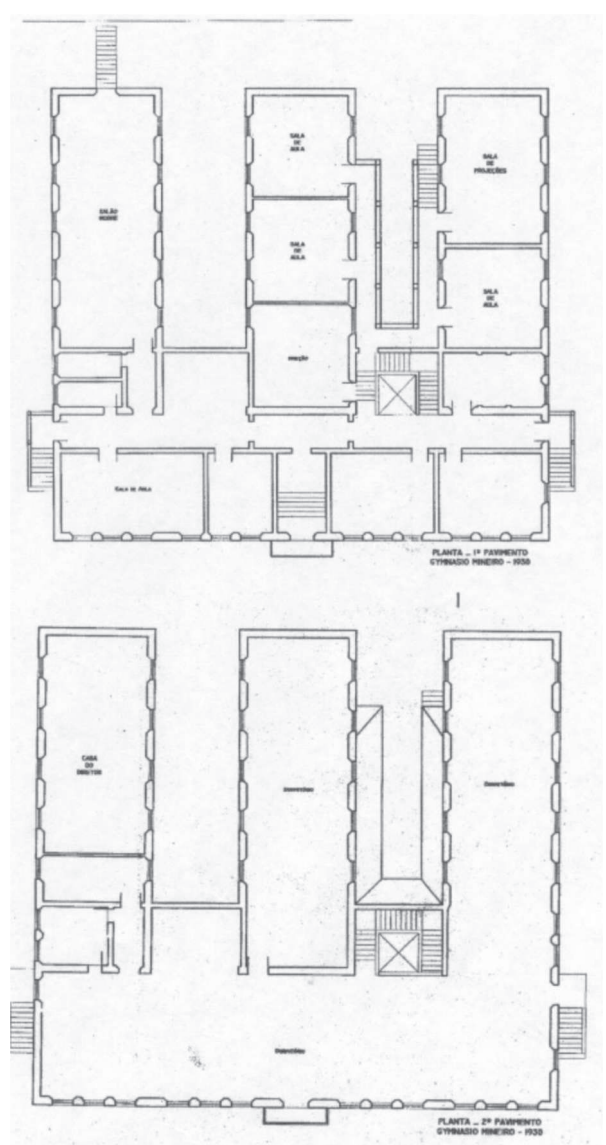

FIGURA 8 - Levantamento métrico-arquitetônico s/ escala da planta do $1^{\circ}$ e do $2^{\circ}$. pavimento do Gymnásio Mineiro, em 1930 (UBERLÂNDIA, 2007a). 
Somente em 1973, o prédio recebeu uma grande reforma por meio da ação da CARPE - Comissão de Construção, Ampliação e Reconstrução de Prédios Escolares do Estado, vinculada ao governo de Minas Gerais. Nessa reforma foi trocado o assoalho de madeira que foi substituído por um de cerâmica e a escada que dá acesso do primeiro ao segundo pavimento que era de madeira foi substituído por uma de concreto. Foi construída no ano de 1974 uma quadra poliesportiva coberta por estrutura metálica.

Em 1980, a escola recebeu várias intervenções de pintura geral, colocação de guarda copo de metal na escada interna, a portaria recebeu grades de proteção, o patamar de acesso à porta lateral esquerda do prédio foi fechado com alvenaria para a instalação de uma copiadora e colocação de grades nas janelas da fachada frontal do primeiro pavimento e foram construídas salas para laboratório em 1981. Em 1992, o prédio recebeu nova pintura, bem como, ao longo dos anos, alguns anexos foram construídos no terreno dos fundos, como a cozinha, a casa do zelador e uma marcenaria.

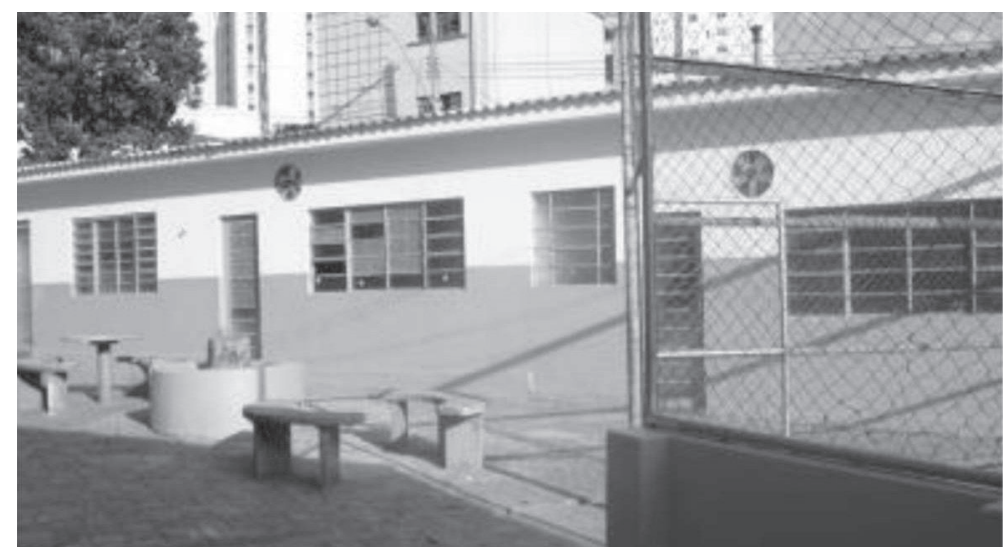

FIGURA 9 - Exemplo de edificações anexas ao prédio original da Escola Estadual Uberlândia(Fotografia de Décio Gatti Júnior, em 11 de julho de 2007).

Em 2006, a escola foi contemplada pelo projeto "Escola Referência" do governo estadual mineiro e, com isso, passou por um grande processo de restauração, sendo que há trinta e três anos o prédio não passava por uma grande reforma. Neste processo recente de restauração, portas e 
janelas foram recuperadas, mantendo suas características originais, a pintura que também estava desgastada pela ação do tempo e pela falta de manutenção também foram recuperadas. No portal de entrada do prédio da escola foram encontrados afrescos que provavelmente fazem parte da pintura original do edifício e que foram cobertos ao longo dos anos por várias camadas de tinta.

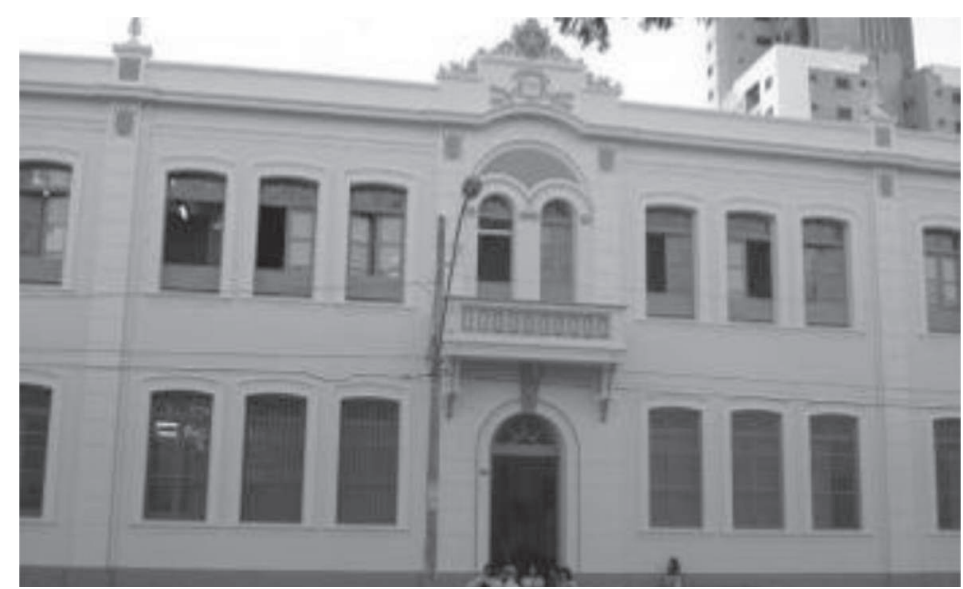

FIGURA 10 - Fachada da Escola Estadual Uberlândia (Fotografia de Décio Gatti Júnior, em 11 de julho de 2007).

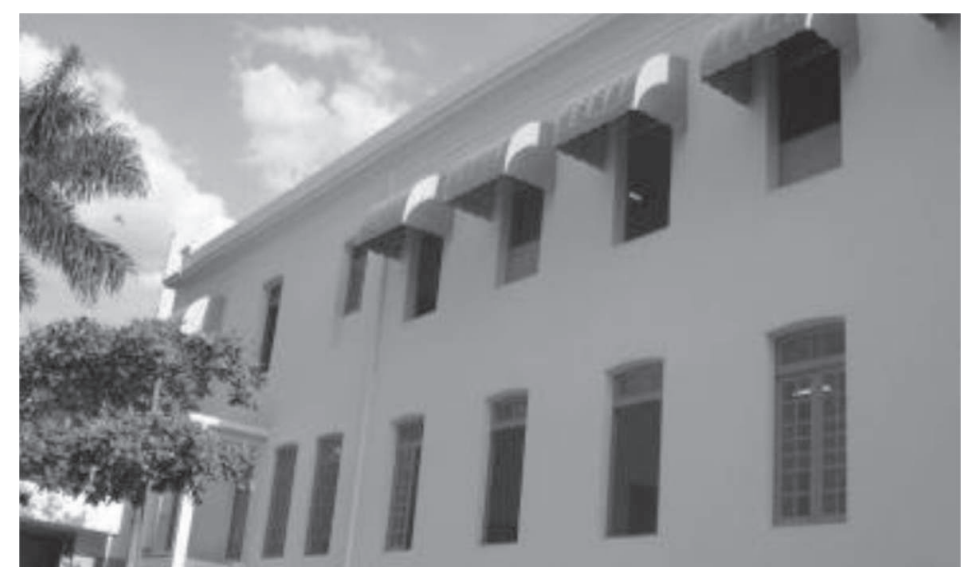

FIGURA 11 - Fachada lateral da Escola Estadual Uberlândia (Fotografia de Décio Gatti Júnior, em 11 de julho de 2007). 
Enfim, o processo de recuperação do prédio da atual Escola Estadual de Uberlândia foi muito importante, pois o edifício marca um momento de desenvolvimento e transformação da antiga cidade de Uberabinha e o prédio construído com a finalidade de abrigar ali uma instituição de ensino tinha por finalidade difundir o conhecimento e formar cidadãos de modo particular, mas em consonância com finalidades sociais mais amplas.

\section{Considerações finais}

Depreende-se da análise exploratória realizada neste artigo que o exame desse conjunto de artefatos escolares que compuseram ao longo do tempo a materialidade das práticas escolares no Ginásio Mineiro de Uberlândia confere base empírica mais consistente ao exame do que ocorria na escola, com resultado benéfico para a confiabilidade da interpretação histórica, na direção da definição dos diferentes sentidos e objetivos sociais assumidos pela escola em sua história.

\section{Referências}

CHERVEL, André (1990). A história das disciplinas escolares: reflexões sobre um campo de pesquisa. Teoria e Educação, Porto Alegre, 1990. n. 2, p. 177-229.

GATTI JR., Décio e PESSANHA, Eurize Caldas (2005). História da Educação, Instituições e Cultura Escolar: conceitos, categorias e materiais históricos. In: GATTI JR., Décio e INÁCIO FILHO, Geraldo (Org.). História da Educação em Perspectiva: ensino, pesquisa, produção e novas investigações. Campinas/SP: Autores Associados. Uberlândia/MG: Editora da Universidade Federal de Uberlândia. p. 71-90.

GATTI, Giseli Cristina do Vale. História e Representações Sociais da Escola Estadual de Uberlândia (1929-1950). Dissertação (Mestrado. Uberlândia/MG: Universidade Federal de Uberlândia, Uberlândia, 2001.

JULIA, Dominique. A Cultura escolar como objeto histórico. Revista Brasileira de História da Educação, v. 1, n. 1, jan./jun. 2001. p. 9-43.

MAGAlHÃES, Justino. Contributo para a História das Instituições

Educ. e Filos. Uberlândia, v. 23, n. 46, p. 119-144, jul./dez. 2009. 
Educativas - entre a memória e o arquivo. Braga-Portugal. Universidade do Minho.1996 s/d. (mimeo.).

Um Apontamento metodológico sobre a História das Instituições Educativas. In SOUZA, C., CATANI, D. (Org.) Práticas Educativas, Culturas Escolares, Profissão docente. II Congresso Luso-brasileiro de História da Educação. São Paulo, Escrituras, 1998.

.AHistória das Instituições Educacionais em Perspectiva. In: GATTI JR., Décio e INÁCIO FILHO, Geraldo (Org.). História da Educação em Perspectiva: ensino, pesquisa, produção e novas investigações. Campinas/ SP: Autores Associados. Uberlândia/MG: Editora da Universidade Federal de Uberlândia, 2005, p. 91-103.

MENDES, Viviane Santana. História e Memória Educacional: a Escola Estadual de Uberlândia (1912-1929). Dissertação (Mestrado em História). Pontifícia Universidade Católica de São Paulo, São Paulo,2000.

NOSELLA, Paolo e BUFFA, Ester. As pesquisas sobre instituições escolares: o método dialético marxista de investigação. EccoS - Revista Científica. São Paulo. v. 7, n. 2, jul.-dez. 2005. p. 351-68.

NÓVOA, Antonio. Apresentação. In: CAMBI, Franco. História da Pedagogia. São Paulo: Editora da Universidade Estadual Paulista. 1999 p. 11-5.

SAVIANI, Dermeval. Instituições Escolares: conceito, história, historiografia e práticas. Cadernos de História da Educação. Número 4. 2005, p. 27 a 33.

UBERLÂNDIA. Prefeitura Municipal. Inventário de Proteção do Acervo Cultural (Minas Gerais - Brasil) Disponível em: http://www2.uberlandia. mg.gov.br/ pmu/jornal/Bens\%20tombados.PDF. Acessado em 12 de setembro de 2007.

UBERLÂNDIA. Prefeitura Municipal. Bens Tombados - Identificação e História. Disponível em: http://www3.uberlandia.mg.gov.br/cidade_ patrimonio. php?id=620. Acessado em 12 de setembro de 2007.

VINÃO FRAGO, Antonio. Historia de la Educación e Historia Cultural: posibilidades, problemas, cuestiones. Revista Brasileira de Educação. 1995 n. 00. Set/Out/Nov/Dez. p. 63-82.

Educ. e Filos. Uberlândia, v. 23, n. 46, p. 119-144, jul./dez. 2009. 
Antonio. El espacio el tiempo escolares como objeto histórico. In: Warde, Mirian Jorge (Org.). Contemporaneidade e Educação. Temas de História da Educação. Rio de Janeiro: Instituto de Estudos da Cultura da Educação, 2000.

Data de registro: 15/02/09

Data de aceite: 18/03/09 
